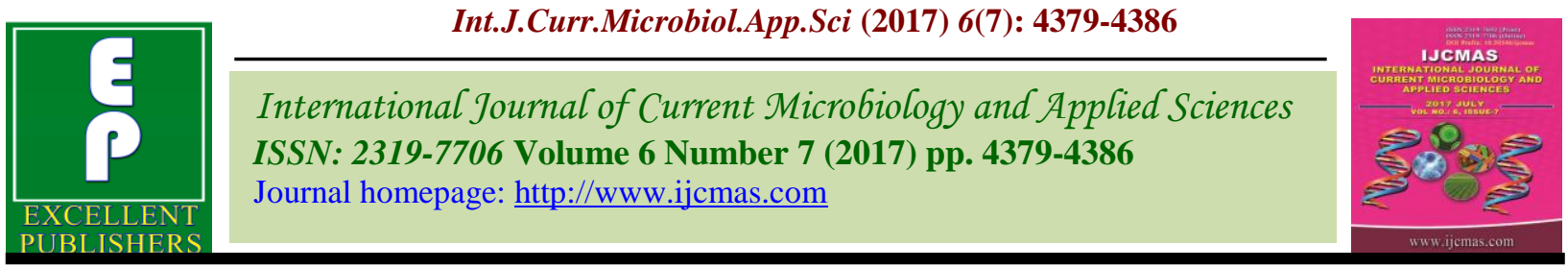

Original Research Article

https://doi.org/10.20546/ijcmas.2017.607.456

\title{
Sperm Mediated Gene Transfer (SMGT) in Chicken
}

\author{
Sushil Kumar*, Govind Mohan, Revanasiddu Deginal, Saleem Yousuf, \\ N. Anand Kumar and P. Sateesh Kumar
}

ICAR-National Dairy Research Institute, Karnal, Haryana-132001, India

*Corresponding author

\begin{tabular}{|c|c|}
\hline & $\boldsymbol{I} \mathbf{R} A \mathbf{C} \mathbf{T}$ \\
\hline & \multirow{6}{*}{$\begin{array}{l}\text { Sperm-mediated gene transfer (SMGT) is a transgenic technique involves transfer of } \\
\text { the genes based on the spermability to bind spontaneously and internalize the } \\
\text { exogenous DNA, and transport it into an oocyte during fertilization to produce genetically } \\
\text { modified animals. Spermatozoa play a major role in transgenesis in virtually all species. } \\
\text { Their ability to take up exogenous DNA molecules to transmit novel genetic information } \\
\text { to the offspring after fertilization can be exploited. The assisted techniques like } \\
\text { electroporation, lipofection, Restriction Enzyme Mediated Integration (REMI), } \\
\text { Intracytoplasmic Sperm injection (ICSI) and linker based SMGT have been developed to } \\
\text { increase the DNA uptake by the spermatozoa. SMGT can be regarded as a potential source } \\
\text { of mutation for the host genome. Avian species, particularly chickens, have been } \\
\text { increasingly used in transgenic research due to their inherent advantages, such as short } \\
\text { generation times, high semen production and potential applications as transgenic } \\
\text { bioreactors for heterologous protein production. The application of transgenic technology } \\
\text { to domestic poultry offers an alternative to conventional practices for the improvement of } \\
\text { this highly productive agricultural species and its use as a bioreactor model. }\end{array}$} \\
\hline & \\
\hline $\begin{array}{l}\text { Sperm Mediated } \\
\text { Gene Transfer, }\end{array}$ & \\
\hline Article Info & \\
\hline $\begin{array}{l}\text { Accepted: } \\
30 \text { June } 2017 \\
\text { Available Onli } \\
10 \text { July } 2017\end{array}$ & \\
\hline & \\
\hline
\end{tabular}

\section{Introduction}

A transgenic animal as originally defined by Gordon and Ruddle (1981), is an organism carrying recombinant molecules that were intentionally introduced by human intervention. Classically this entailed the stable integration of the transgene within the host animal's genome and its transmission to progeny through normal breeding programmes. Transgenic chicken holds great promise in basic biological research and in industrial applications. Beyond their intrinsic value as model systems in biological research, transgenic chickens hold promise in many commercial and industrial applications. Chickens deposit large amounts of proteins into their eggs (Ivarie, 2003). A transgenic chicken could conceivably function as a bioreactor for the production of commercially or pharmaceutically important proteins, which are difficult or impossible to produce economically in prokaryotic systems. Gene transfer technology may also prove to be a useful complement to traditional poultry breeding methods in the improvement of commercially important production traits such as growth and disease resistance. Both intra and inter-species transfer could be used to introduce genes controlling desirable physiological functions unavailable in the existing pool of genetic variation (Etches, 
1993). A number of different strategies designed to allow the manipulation of the avian genome have been investigated with varying degrees of success.

\section{Sperm Mediated Gene Transfer (SMGT)}

Sperm Mediated Gene Transfer (SMGT) is based on the ability of sperm cells to bind and internalize exogenous DNA and to transfer it into eggs at fertilization. The first report on production of transgenic animal by stable integration of foreign DNA by SMGT and its transmission to the progenies by Mendelian inheritance was provided by Lavitrano et al., (1989) in mice. This report was of considerable interest to biologists, and numerous efforts have been made to duplicate these experiments and since then, both positive and negative reports periodically appeared in the literature. In an effort to repeat the experiments, Brinster et al., (1989), carried out transfection experiments under similar conditions, but out of 1300 mice produced using SMGT technique; none have been shown to posses the foreign DNA. However, successful genetic transformation of mice by Lavitrano et al., (1989) was quickly followed by successful sperm genetransfer experiments in the mouse at the embryonic (Hochi et al., 1990) and adult stage (de la Fuente et al., 1991), as well as in other species, such as bovine (Perez et al., 1991), sea urchins (Arezzo, 1989), insects (Milne et al., 1989), and birds (Feinsod et al., 1990) were reported within a span of two years. However, the reason for the controversial results obtained so far may possibly be due to varied experimental conditions in which experiments were performed with sperm cells of different species. The first report on SMGT in chicken appeared in the literature in 1990 (Feinsod et al., 1990). Subsequently, DNA uptake by chicken spermatozoa has been demonstrated by several workers (Gavora et al., 1991;
Castro et al., 1991; Gruenbaum et al., 1991; Rottmann et al., 1992; Trefil et al., 1992; Nakanishi and Iritani, 1993; Rottmann et al., 1996; Yang et al., 2004). Binding efficiency ranged from $6.3 \%$ (Nakanishi and Iritani, 1993) to 25\% (Castro et al., 1991).

\section{Factors influencing SMGT}

Since the SMGT is based on the ability of sperm cells to bind and internalize exogenous DNA, the size, shape of exogenous DNA, quantity and quality of spermatozoa, incubation temperature and time are crucial factor influencing the efficiency of SMGT.

\section{Form of DNA}

Linear form of DNA was predominantly used in the transfection experiments. The reason for this could that circular molecules may be exposed to a higher degree of rearrangement during the processes of linearization and integration than are linear molecules, which may be integrated in a more direct way using their free ends. In an attempt to produce transgenic mice, to date, majority of the workers used only linear DNA molecules for sperm transfection (Gavora et al., 1991, Rottmann et al., 1992, 1996; Lavitrano et al.,, 2002, 2003; Shemesh et al., 2000 Cho, et al., 2002; Yang et al., 2004).

\section{Size of DNA}

Lavitrano et al., (1992) observed that DNA molecules of large size $(7 \mathrm{~kb})$ were preferentially taken up by mice epididymal sperm cells as compared to smaller ones (150750bp). Barring this report, no other comparative study on size of DNA and their efficiency on transfection is available in the literature. Bachiller et al., (1991) obtained similar pattern of localization of exogenous DNA on the nucleus with DNAs varying in size from 1.8 to $14 \mathrm{~kb}$. Isolated gene 
constructs like human erythropoietin gene as a $5.86 \mathrm{~kb}$ fragment of pZIP(X) and bacterial LacZ gene as a $5.84 \mathrm{~kb}$ fragment of pCH110 (Cho et al., 2002) and Green fluorescent protein gene as a $3.3 \mathrm{~kb}$ fragment of pCXEGFP (Yang et al., 2004) have also been used in sperm mediated gene transfer studies. Recently, transgenic pigs expressing human decay accelerating factor have been successfully produced by transferring a linearized plasmid of $6.8 \mathrm{~kb}$ size containing hDAFminigene construct (Lavitrano et al., 2002). Churchil used three types of exogenous DNA inserts, i.e. complete linearised $\mathrm{pVIVO} 2-\mathrm{GFP} / \mathrm{LacZ}$ vector (9620bp), the LacZ gene (5317bp) and the GFP gene (2152bp) with equal efficacy to transfect chicken spermatozoa.

\section{Amount of DNA}

Scanning the literature revealed wide variations in amount of DNA used for SMGT. The quantity of DNA used by most of the workers was around $10 \mu \mathrm{g}$ per 100 million sperm cells (Rottmann et al., 1996; Cho et al., 2002; Yang et al., 2004); however as high as $40 \mu \mathrm{g}$ DNA per 100 million swine sperm cells (Lavitrano et al., 2003) and $100 \mu \mathrm{g}$ DNA per 100 million mice sperm cells (Gavora et al., 1991) have also been reported.

\section{Time and temperature of incubation}

In general, the sperm cells were allowed to interact with DNA for longer duration (1 hr or more) when they were to be subjected for uptake studies rather than for artificial insemination (less than $1 \mathrm{hr}$ ) (Yang et al., 2004). Owing to the sudden motility depression of semen of avian species on storage, spermatozoa from chicken is generally subjected to low temperature and short duration incubation (Yang et al., 2004) compared to other species like pigs (Lavitrano et al., 2003).

\section{Quality of spermatozoa}

It is therefore, the DNA uptake experiments are generally conducted with highly motile spermatozoa (90\% or more) (Rottmann et al., 1992; Zoraqi and Spadafora, 1997; Carballada and Esponda, 2001). The quality of sperm evaluated by standard procedures is directly correlated to the outcome of sperm-DNA interaction (Lavitrano et al., 2002). The quality of semen based on standard parameters used in conventional animal breeding programs (volume, concentration, presence of abnormal sperm cells, motility at time of collection, and high progressive motility after $2 \mathrm{hr}$ ) are the best indicators for the ability of the sperm cells to take up and internalize exogenous DNA (Lavitrano et al., 2003).

\section{DNaseI treatment}

To discriminate between the binding of DNA to the sperm surface and DNA that has been internalized, Bachiller et al., (1991) used radioactive label as a means to follow DNA and DNase treatment to differentiate between binding and uptake. They treated the sperm with DNase to destroy all DNA bound at the surface of the sperm cells, The sperm was then washed again and the counts associated with the sperm after DNase treatment were considered as protected by internalization into the sperm head or tail. Rottmann et al., (1992) added 100 units of DNase to the solution containing $100 \mu \mathrm{g}$ of exogenous DNA and 120 million chicken sperm cells in $1 \mathrm{ml}$ volume.

\section{Inhibitory factors of semen}

Experiments performed in mammals have clearly shown that ejaculate spermatozoa are impermeable to foreign DNA unless seminal plasma is thoroughly removed. Inhibitory factor I (IF-I), originally identified in echinoid spermatozoa and in mouse seminal plasma as a $37-\mathrm{kDa}$ DNA-binding glycoprotein 
appeared to be the specific target through which the inhibition was mediated. Seminal plasma of mice is also found to have DNase activity (Carballada and Esponda, 2001). Although chickens have no accessory glands, spermatozoa from the ejaculated contain seminal plasma. Recently, Sato et al., (2003) reported the presence of DNase activity in the seminal plasma of ejaculated chicken semen. However, the DNA entrapped in liposomes was protected from the DNase activity of seminal plasma. Heat treatment at $70^{\circ} \mathrm{C}$ for 5 min and addition of EDTA at least $0.5 \mathrm{mM}$ per litre were found to remove the DNase activity of the chicken seminal plasma.

\section{Semen diluents}

Phosphate buffer saline (PBS) has been used for washing the spermatozoa irrespective of species (Hasebe et al., 1998; Carballada and Esponda, 2001), but the use of BPSE (Gavora et al., 1991; Squires and Drake, 1993), Salt TES medium (Trefil et al., 1992) and KrebsRinger-solution (Rottaman et al., 1996) in chicken has been reported in literature.

Internalization and integration of exogenous DNA

Many reports provide convincing data indicating that part of the bound DNA is internalized into the sperm cell and may be found within its nucleus (Bachiller et al., 1991; Camaioni et al., 1992; Francolini et al., 1993). Lavitrano et al., (2003) reported that approximately $20 \%$ of the DNA bound to the sperm was internalized into the sperm nuclei. The role of $\mathrm{CD} 4$ antigen molecules in internalization of foreign DNA has been demonstrated by Lavitrano et al., (1997). They observed that although the spermatozoa from CD4 knockout mice were capable of binding exogenous DNA, they lost the ability to further internalize it. The heavy rearrangement and recombination of foreign DNA with the genomic DNA (Zoraqi and
Spadafora, 1997) suggested that the exogenous DNA is exposed to the action of endonucleases early after internalization. In the same year, Maione et al., (1997) demonstrated that the sperm nucleus is an unsafe place for exogenous DNA since its internalization activates a metabolically active process similar to apoptosis which destroys both the DNA and the sperm cell. The nucleases were activated in response to the internalization of exogenous DNA by mice and swine sperm cells and their activity increased with the DNA concentration. Nuclease activation was efficient in epididymal sperm cells, while being drastically reduced in ejaculated washed spermatozoa. Moreover, nuclease activation also caused a partial degradation of the sperm endogenous chromosomal DNA; cleaved DNA fragments were released from the sperm cells to the medium. Taken together, the results of this study suggested that a metabolically active process similar to apoptosis is triggered in the nuclei of mature sperm cells upon interaction with exogenous DNA. Sequence analysis of two randomly selected clones independently recovered by plasmid rescue from pSV2CAT plasmidchallenged sperm cells showed that DNA fragments from the plasmid were integrated into the mouse sperm genome. The sites of integration were identical in both clones, suggested that these events do not occur randomly, but take place at preferential sites. A topoisomerase II consensus sequence was found adjacent to one end of the integration site, suggesting a possible role of this enzyme in the process of nonhomologous recombination.

\section{Transfection methods}

\section{Electroporation}

Horan et al., (1992) attempted electroporation in pigs, a large mammal in which $70 \%$ of motile spermatozoa incorporated exogenous 
DNA in the postacrosomal region after simple incubation. When this technique was used the DNA amount bound to sperm increased by 5\%-10\%. More interestingly, Rieth et al., (2000) recently showed that homologous recombination is also possible using SMGT in cattle. The transgenic embryos were obtained after electroporating sperm with DNA constructs which carrying a reporter gene and a highly repetitive sequence i.e. Alu-like repeat known to favor transgenesis by homologous recombination. Analysis by PCR revealed that $46.5 \%$ of the transgenic embryos showed homologous recombination events, compared to only $3.5 \%$ in the absence of electroporation. Therefore, the use of this new, promising technique in addition to or instead of the use of embryonic sperm cells can be envisaged in the near future to produce knockout animals, especially in large mammals.

\section{Lipofection}

Liposome is small bodies consisting of membrane-like lipid layers surrounding hydrous compartments. Liposomes have been used for a long time to introduce a variety of molecules into living cells (Gregoriadis and Allison, 1980), but their utility as a carrier for nucleic acids was quite limited. A new type of liposomes made of cationic lipids was developed (Felgner et al., 1987; Behr et al., 1989) and DNA-cationic lipid complexes (lipoplexes) possess a number of desirable properties and have become perhaps the most popular utilities for this purpose (Felgner et al., 1987). Importantly, such complexes are nonimmunogenic, nonpathogenic, biodegradable, and easy to prepare. Furthermore, liposome can be used to protect a foreign DNA from digestion of proteases or DNase I present in the cytoplasm of egg (Schaeffer-Ridder et al., 1982). Commercial available liposome can spontaneously interact with RNA/DNA and fuse with the plasma membrane in a wide variety of cell types in culture to produce transfections (SchaefferRidder et al., 1982; Francolini et al., 1993). The cationic outer surfaces of the complex can then associate with the negatively charged cell membrane, allowing the internalization of the nucleic acid. These new type pf liposomes turned out to be very efficient in the transfer of DNA into cells. Efficiency of liposomes in increasing the exogenous uptake by spermatozoa has been shown by various workers in chicken (Rottmann et al., 1992, Squires and Drake, 1994; Nakanishi and Iritani, 1993; Yang et al., 2004, HarelMarkowitz et al., (2009), Churchil et al., 2011; ElGendy et al., 2013).

\section{Restriction enzyme-mediated integration (REMI)}

A new method for integrating exogenous DNA into cells is restriction enzyme mediated integration. REMI utilizes a linear DNA that is derived from a plasmid DNA by cutting that plasmid with a restriction enzyme to generate single-stranded cohesive ends. The linear, cohesive-ended DNA, together with the restriction enzyme is then introduced into the target cells by lipofection or electroporation. The corresponding restriction enzyme is then thought to cut the genomic DNA at sites that enable the exogenous DNA to integrate via its matching cohesive ends (Kuspa and Loomis, 1996). Transgenic bovine sperm were produced by restriction enzyme mediated insertion (REMI) by Shemesh et al., (2000) utilizing lipofection of linearized pEGFP and the corresponding restriction enzyme for integration into the sperm genomic DNA. In chicken, Yang et al., (2004), Harel-Markowitz et al., (2009) and Churchil et al., (2011) have successfully used REMI.

\section{Receptor-mediated gene transfer}

Receptor-mediated gene transfer was first demonstrated by $\mathrm{Wu}$ and $\mathrm{Wu}$ (1989) using 
polycation-conjugated asialoglycoprotein. The positive charges allowed binding to DNA's, large polyanionic molecules. This strategy had been successfully applied to many receptors and cells in vitro and in vivo using antibodies, transferrin, asialofetuin, galactose, folate, and other proteins (peptides) or carbohydrates (reviewed by Varga et al., 2000; Anwer et al.,2000). DNA coupled with antibodies or antibody-fragments offer the ability to target the selected cells and facilitate internalization of the complexes via receptormediated endocytosis. If a sperm reactive antibody with a basic region could be identified, it may possibly serve as a benign biological cross-linker between DNA and sperm.

\section{Transmission of exogenous DNA to embryos and progeny}

Lavitrano et al., (1989) obtained transgenic mice using sperm cells as foreign DNA vectors. F1 progeny from their experiment showed paternal and maternal transmission of the transgene from the founders. They suggested that the differently rearranged and/ or episomal copies of the pSV2CAT plasmid might be present in the transgenic mouse genome. CAT (chloramphenicol acetyl transferase) gene expression was detected on tissues of adult F1 individuals, preferentially on tails and muscle. Subsequent studies failed to show presence of exogenous DNA in progenies (Arezzo, 1989; Gavora et al., 1991; Bachiller et al., 1991).

A large number of $\mathrm{hDAF}$ transgenic pigs were generated by using SMGT by Lavitrano et al., (2002). In these experiments, up to $80 \%$ of pigs had the transgene integrated into the genome. Most of the pigs carrying the hDAF gene transcribed it in a stable manner (64\%). The great majority of pigs that transcribed the gene expressed the protein (83\%). The hDAF gene was transmitted to progeny. Expression was stable and found in caveolae as it is in human cells. The expressed gene was functional based on in vitro experiments performed on peripheral blood mononuclear cells.

Wang et al., (2003) reported that $\beta$ galactosidase was expressed in different stages of embryo development and in the tissues of young rabbit as detected by using $\mathrm{X}$-gal staining. Transgene integration was further verified by PCR analysis. These results confirmed the ability of rabbit sperm cells to carry transgene into the embryo during in vitro fertilization.

Yang et al., (2004) screened the chicks using PCR and found 2 out 21chicks (9.5\%) from treatment used liposome like compound and 2 out of 53 chicks (3.7\%) from treatment used liposome for transfection were transgenic. Harel-Markowitz et al., (2009) reported detection of the transgene for human FSH (PCR) and expression of the gene (RT-PCR and quantitative real-time $\mathrm{PCR}$ ) and the presence of the protein in blood (radioimmuno-assay) in chicken for two generations following insemination with sperm lipofected with p-hFSH. Collares et al., (2011) produced transgenic chick using enhanced green fluorescent protein (EGFP) as exogenous DNA and dimethylsulfoxide (DMSO) or N,N-dimethylacetamide (DMAc) as transfectants. PCR analysis detected the presence of EGFP DNA in 38\% of newborn chicks from the DMSO group and 19\% from the DMAc group. EGFP mRNA was detected in $21 \%$ of newborn chicks from the DMSO group, as against $8.5 \%$ from the DMAc group. However, in vivo expression of EGFP was only observed in a single animal from the DMSO group. ElGendy et al., (2013) successfully showed the presence of transgene in F1 progenies. The positively detected SMGT-derived offspring formed 40.0 to $50.0 \%$ of the $\mathrm{F} 1$ generation. 


\section{Assisted SMGT}

The initial reports on SMGT, carried out by simple incubation of exogenous DNA with spermatozoa (Brackett et al., 1971; Lavitrano et al., 1989; Areezo, 1989; Brinster et al., 1989), but later the assisted techniques like electroporation, lipofection, Restriction Enzyme Mediated Integration (REMI), Intracytoplasmic Sperm injection (ICSI) and linker based SMGT have been developed. These assisted techniques are found to increase the DNA uptake by the spermatozoa. Despite these modifications, the native SMGT is still being preferred by many workers.

In conclusion, over the past decades, SMGT has drawn the attention of many researchers in the ongoing debate on transgenic chicken. In spite of its having become a well accepted \& established method, SMGT is still subjected to development and new approaches are being developed to make the technique even more widespread and reliable. Given the wide availability of semen, SMGT can considered the method of choice for the production of genetically modified chicken $\&$ represents the most powerful tool available today. In conclusion, SMGT is an efficient \& inexpensive method that will hopefully facilitate the implementation of strategies for securing the benefits that can be expected to arise from the introduction of transgenic chicken.

\section{References}

Anzar, M. and Buhr, M.M. 2006. Spontaneous uptake of exogenous DNA by bull spermatozoa. Theriogenol., 65: 683-690

Campos, V.F., Collares, T., Seixas, F.K., Kaefer, K., Cavalcanti, P.V., Amaral, M., Lucia, T.Jr, and Deschamps, J.C. 2010b. Association between the presence of a $38 \mathrm{kDa}$ factor in the seminal plasma and inhibition of sperm motility in the jundia fish Rhamdiaquelen. Ci. Anim. Bras., 11: 402-409

Canovas, S., Gutierrez-Adan, A. and Gadea, J. 2010. Effect of exogenous DNA on bovine sperm functionality using the sperm mediated gene transfer (SMGT) technique. Mol. Reprod. Dev., 77: 687698.

Chalah, T., Seigneurin, F., Blesbois, E., Brillard, J.P. 1999. In vitro comparison of fowl sperm viability in ejaculates frozen by three different techniques and relationship with subsequent fertility in vivo. Cryobiol., 39: 185-191.

Churchil. 2005. Development of transgenic spermatozoa in chicken, Ph.D., thesis submitted to the Indian veterinary Research institute, Izatnagar, Bareilly, Uttar Pradesh, India.

Collares, T., Campos, V.F., Seixas, F.K., Cavalcanti, P.V., Dellagostin, O.A., Moreira, H.L. and Deschamps, J.C. 2010. Transgene transmission in South American catfish (Rhamdiaquelen) larvae by spermmediated gene transfer. J. Biosci., 3539-47.

Ebara, F. and Fujihara, N. 1999. Reproductive characteristics of transgenic (TG) chickens carrying an exogenous gene. Asian J. Androl., 1139-144.

Ebara, F. and Fujihara, N. 1999. Reproductive characteristics of transgenic (TG) chickens carrying an exogenous gene. Asian J. Androl., 1: 139-144.

Evaluation of amides and centrifugation temperature in boar semen cryopreservation. Theriogenol., 69: 632-638.

Garcia-Vazquez, F.A., Garcia-Rosello, E., Gutierrez-Adan, A. and Gadea, J. 2009. Effect of sperm treatment on efficiency of EGFP-expressing porcine embryos produced by ICSI-SMGT. Theriogenol., 
72: 506-518.

Gavora, J.S., Benkel, B., Sasada, H., Cantwell, W.J., Fiser, P., Teather, R.M., Nagai, J. and Sabour, M.P. 1991. An attempt at sperm-mediated gene-transfer in mice and chickens. Can. J. Anim. Sci., 71: 287-291.

Han, J.Y. 2009. Germ cells and transgenesis in chickens. Comp Immunol. Microbiol. Infect. Dis., 32: 61-80.

Harel-Markowitz, E., Gurevich, M., Shore, L.S., Katz, A., Stram, Y. and Shemesh, M. 2009. Use of sperm plasmid DNA lipofection combined with REMI (restriction enzymemediated insertion) for production of transgenic chickens expressing eGFP (enhanced green fluorescent protein) or human folliclestimulating hormone. Biol. Reprod., 80: 1046- 1052.

Howarth, B., Jr. 1983. Comparison of diluents for holding cock semen six hours at 41 C. Poult. Sci., 62: 1084-1087.

Kang, J.H., Hakimov, H., Ruiz, A., Friendship, R.M., Buhr, M. and Golovan, S.P. 2008. The negative effects of exogenous DNA binding on porcine spermatozoa are caused by removal of seminal fluid. Theriogenol., 70: 1288-1296.

Kim, T.S., Lee, S.H., Gang, G.T., Lee, Y.S., Kim, S.U., Koo, D.B., Shin, M.Y., Park, C.K. and Lee, D.S. 2009. Exogenous DNA uptake of boar spermatozoa by a magnetic nanoparticle vector system. Reprod. Domest. Anim., 45: e201-e206. Kuznetsov, A.V., Kuznetsova, I.V. and Schit, I.Y. 2000. DNA interaction with rabbit sperm cells and its transfer into ova in vitro and in vivo. Mol. Reprod. Dev., 56: 292-297.

Lanes, C.F., Sampaio, L.A. and Marins, L.F. 2009. Evaluation of DNase activity in seminal plasma and uptake of exogenous DNA by spermatozoa of the Brazilian flounder Paralichthysorbignyanus. Theriogenol., 71: 525-533.

Latorre, J.R., Harris, G.C., Jr and Johnson, Z.B. 1988. Influence of storage container for frozen-thawed chicken semen and frequency of insemination on fertility and its duration. Poult. Sci., 67: 333-335.

Lavitrano, M., Camaioni, A., Fazio, V.M., Dolci, S., Farace, M.G. and Spadafora, C. 1989. Sperm cells as vectors for introducing foreign DNA into eggs: genetic transformation of mice. Cell, 57: 717-723.

Nano SMGT: transfection of exogenous DNA on sex-sorted bovine sperm using nanopolymer. Theriogenol., 75: 14761481.

Sexton, T. 1982. Beltsville poultry semen extender. 6. Holding turkey semen for six hours at 15C. Poultry Sci., 61: 1202-1208.

Shaffer, C.S., Henderson, E.W., Card, C.G. 1941. Viability of spermatozoa of the chicken under various environmental conditions. Poultry Sci., 20: 259-265.

Thoraval, P., Trefil, P., Dambrine, G. 2000. Inoculation of foreign DNA into testes of young cocks of domestic poultry (Gallus domesticus). Czech J. Anim. Sci., 45: 289-292.

\section{How to cite this article:}

Sushil Kumar, Govind Mohan, Revanasiddu Deginal, Saleem Yousuf, N. Anand Kumar and Sateesh Kumar, P. 2017. Sperm Mediated Gene Transfer (SMGT) in Chicken. Int.J.Curr.Microbiol.App.Sci. 6(7): 4379-4386. doi: https://doi.org/10.20546/ijcmas.2017.607.456 